\title{
BIOÉTICA AMBIENTAL E EDUCAÇÃO AMBIENTAL: LEVANTANDO A REFLEXÃO A PARTIR DA PERCEPÇÃO
}

Marta Luciane Fischer ${ }^{1}$

Lays Cherobim Parolin ${ }^{2}$

Thalita Bastida Vieira ${ }^{3}$

Flávia Roberta Amend Gabardo 4

Resumo: A bioética ambiental visa despertar a compreensão de certo e errado enquanto condutas ambientais, cuja informação e sensibilização são insuficientes. Objetivou-se avaliar a percepção ambiental de população vizinha a Unidades de Conservação, em Morretes, PR. Os entrevistados evidenciaram percepção positiva das áreas verdes, sendo a possibilidade de ecoturismo e o antropocentrismo mais evidentes na área rural, e a ética biocêntrica na área urbana; perceberam pouca degradação ambiental e relacionaram os animais silvestres à sua função ecológica, indicando poucos malefícios. A análise da percepção ambiental possibilita compreender a relação homem/natureza e subsidiar desenvolvimento de ações em conservação através da educação ambiental e de princípios da bioética ambiental.

Palavras-chave: Antropocentrismo; Biocentrismo; Morretes; Unidade de Conservação.

revista brasileira educação ambiental
${ }^{1}$ Pontifícia Universidade Católica do Paraná. E-mail: marta.fischer@pucpr.br

2 Pontifícia Universidade Católica do Paraná. E-mail: lays.parolim@pucpr.br

3 Universidade Federal do Paraná. E-mail: thalivieira@gmail.com

${ }^{4}$ Pontifícia Universidade Católica do Paraná. E-mail: flavia.amend@gmail.com. 


\section{Introdução}

A crise ecológica e o eminente colapso ambiental, consequência do distanciamento entre o homem e a natureza, tem se intensificado nas últimas décadas reorientando assim a história do planeta. Isto demanda limite no crescimento populacional, havendo aumento na desigualdade social, pobreza, desequilíbrio ecológico, degradação dos recursos hídricos, caotização do espaço urbano, carência de saneamento básico, consumo irresponsável e vulnerabilidade do cidadão diante da destruição do ambiente (LEFF, 2001; SIQUEIRA-BATISTA et al. 2009). Porém, para que soluções sejam alcançadas, é necessário promover mudança na conduta da sociedade, ultrapassando a sensibilização sobre os riscos e consolidando o resgate de laços humano/natureza (MARIN et al. 2003). Dentre as possibilidades de ação, temse a criação de Unidades de Conservação (UCs), cujo planejamento legal e ético visa a exploração sustentável dos recursos naturais em condições e áreas à parte das unidades de preservação (BRASIL, 2014).

A retomada dos valores éticos que norteiam o restabelecimento do convívio harmonioso com a natureza é fundamental para que todas as espécies presentes e suas futuras gerações tenham a oportunidade de desfrutar de um ambiente saudável. O início da década de 1970 marca o surgimento da bioética, uma nova ciência, que a partir das ideias de filósofos como Fritz Jahr em 1927, conduziram Van Rensslaer Potter a propor a Ética da vida (POTTER, 1970). Potter (1970) vislumbrou uma ponte conectando a filosofia e a biologia, subsidiando assim a elaboração de respostas diante da deterioração das relações homem/natureza e resgate de princípios éticos, considerando que: a) todos os seres vivos são interdependentes; b) a natureza é finita; c) é necessária a convivência pacífica com o natural e, por fim, d) o respeito à natureza seja incorporado como missão política, ética e jurídica.

O meio acadêmico conduziu a aplicação bioética na área clínica, voltada para preservação da dignidade humana diante das vulnerabilidades impostas pela pesquisa e exercício da medicina. Contudo, nos últimos anos tem sido retomada sua vocação ecológica, com intuito de conduzir o ser humano a se perceber como corresponsável na manutenção da vida no planeta, através da compreensão do valor intrínseco da natureza e não apenas do instrumental (SIQUEIRA-BATISTA et al. 2009). Desta forma, a bioética ambiental visa a promoção do diálogo entre as ciências biológicas, sociais, econômicas, filosóficas e também a escala jurídica. Assim, problemas tradicionais e contemporâneos podem ser discutidos sob diferentes enfoques e conduzirem o cidadão e a comunidade a conceberem novas condutas na sua relação com a natureza.

Ao instituir a bioética ambiental procura-se despertar no cidadão a compreensão do certo e errado quanto às suas condutas ambientais diante de práticas culturais consolidadas, cuja informação e sensibilização são insuficientes, sendo necessário reeducar (CARVALHO, 2004). A educação ambiental visa subsidiar a compreensão da complexidade do ambiente e viabilizar a reaproximação sujeito/ambiente (SAUVE, 2005). Entretanto, antes 
de instituir políticas de conservação e de educação ambiental, deve-se diagnosticar a percepção da comunidade, já que a sensibilização é decorrente da representação que fazem do ambiente, valores, identidades, interpretações, suas fontes de satisfação e insatisfação estabelecidas através das relações e conhecimentos acumulados ao longo da vida (SILVA-FILHO; BRAGA, 2008; OLIVEIRA; CORONA, 2008; LEITE et al. 2015). Além disso, a percepção, identificação e classificação dos elementos naturais recebem influência do significado emotivo (SANTOS-FITA; COSTA-NETO, 2007), demandando intervenções com bases locais (OLIVEIRA; CORONA, 2008).

A compreensão das diferenças na percepção entre culturas ou grupos socioeconômicos que desempenham funções distintas em um mesmo ambiente é fundamental para o estabelecimento de políticas ambientais que de fato promovem o bem-estar biopsicossocial de todos (FERNANDES et al. 2004; OLIVEIRA; CORONA, 2008). As pesquisas têm caracterizado a percepção avaliando o grau de conhecimento ou percepção sensorial, todavia, são poucos os estudos que têm visado a identificação das concepções éticas, mesmo sendo a valoração atribuída à natureza fundamental de modo a conhecer o objeto de estudo e direcionar as intervenções. Ações de educação ambiental ou implementações de políticas públicas têm pouco efeito ou ação demorada sem as adequações das condutas da comunidade. Para tal, é necessário que a valoração atribuída aos elementos naturais seja condizente com as demandas conservacionistas. A promoção do debate através da bioética ambiental visa minimizar dilemas éticos envolvidos na tomada de decisão. Neste contexto, o presente estudo procura responder como o reconhecimento dos valores, ações, conceitos e identificação das relações éticas entre os sujeitos-atores e o ambiente cotidiano podem subsidiar as intervenções, a fim de ultrapassar os riscos e ameaças decorrentes da necessidade de preservação ambiental.

Nesta perspectiva, objetivou-se avaliar a percepção ética da população rural e urbana de Morretes, Paraná, a respeito do ambiente. A área de estudo foi escolhida devido à proximidade com a natureza decorrente da existência de inúmeras UCs (IAP, 2014). Ademais, o município possui potencial atuação na conservação, construção de políticas ambientais adequadas e fornecimento de informações sobre a fauna e a flora (ARRUDA, 1999). Assim, através de uma análise quali-quantitativa visou-se subsidiar a reflexão da importância da percepção e bioética ambiental no contexto das políticas de conservação, hipotetizando que mesmo a partir de uma pequena amostra já é possível detectar valorações distintas.

\section{Material e Métodos}

\section{Área de Estudo}

O município de Morretes situa-se na zona fisiogeográfica do Litoral Paranaense, possui território de $684.580 \mathrm{~km}^{2}$ e população estimada em 16.325 habitantes, sendo $45,6 \%$ deles na área urbana e $54,4 \%$ na rural. Estende-se da encosta da Serra do Mar fazendo divisa com São José dos Pinhais, Piraquara, 
Quatro Barras, Antonina, Paranaguá e Guaratuba (IBGE, 2014) (Figura 1). Os primeiros moradores chegaram em 1646, originários do Sudeste, em busca das jazidas de ouro; entretanto, o povoamento ocorreu lentamente, sendo reconhecido como cidade apenas em 1869, com o nome Nhundiaquara. Em 1870 , recebeu o nome atual graças ao fato de estar cercado por morros de pequena elevação, ou "morretes" (IBGE, 2014). O município é conhecido como a "Capital Agrícola" da região litorânea paranaense, tendo o maracujá e o pepino como principais cultivos. Entretanto, o setor de serviços e comércio é impulsionado pelo turismo e exerce um importante papel na economia local, contribuindo com mais de 50\% do PIB municipal (BASTARDZ, 2009).

O clima é o Cfa, subtropical superúmido mesotérmico (Köeppen) com verões quentes. A cidade situa-se no Bioma Mata Atlântica, sendo contemplada com a Floresta Ombrófila Densa de Terras Baixas, Sub-Montana, Montana e Alto-Montana (BASTARDZ, 2009). De acordo com levantamento realizado na porção sul da Serra do Mar, possui 93 espécies de mamíferos, correspondendo à 73\% das espécies do Estado (IPARDES, 1991).

O município de Morretes foi beneficiado com inúmeras UCs (IAP, 2014), criadas a partir da década de 1980, com objetivo de proteger os remanescentes de Floresta Atlântica do Paraná e no caso da APA de Guaratuba, compatibilizar o uso racional dos recursos ambientais (IAP, 2014). A Área Especial de Interesse Turístico do Marumbi (AEIT do Marumbi) e a Área de proteção Ambiental de Guaratuba (APA DE Guaratuba) destacam-se pela extensão e juntas representam cerca de 267.000 hectares de terras protegidas, além do Parque Estadual da Graciosa que possui toda sua extensão na cidade de Morretes (IAP, 2014) (Figura 1).
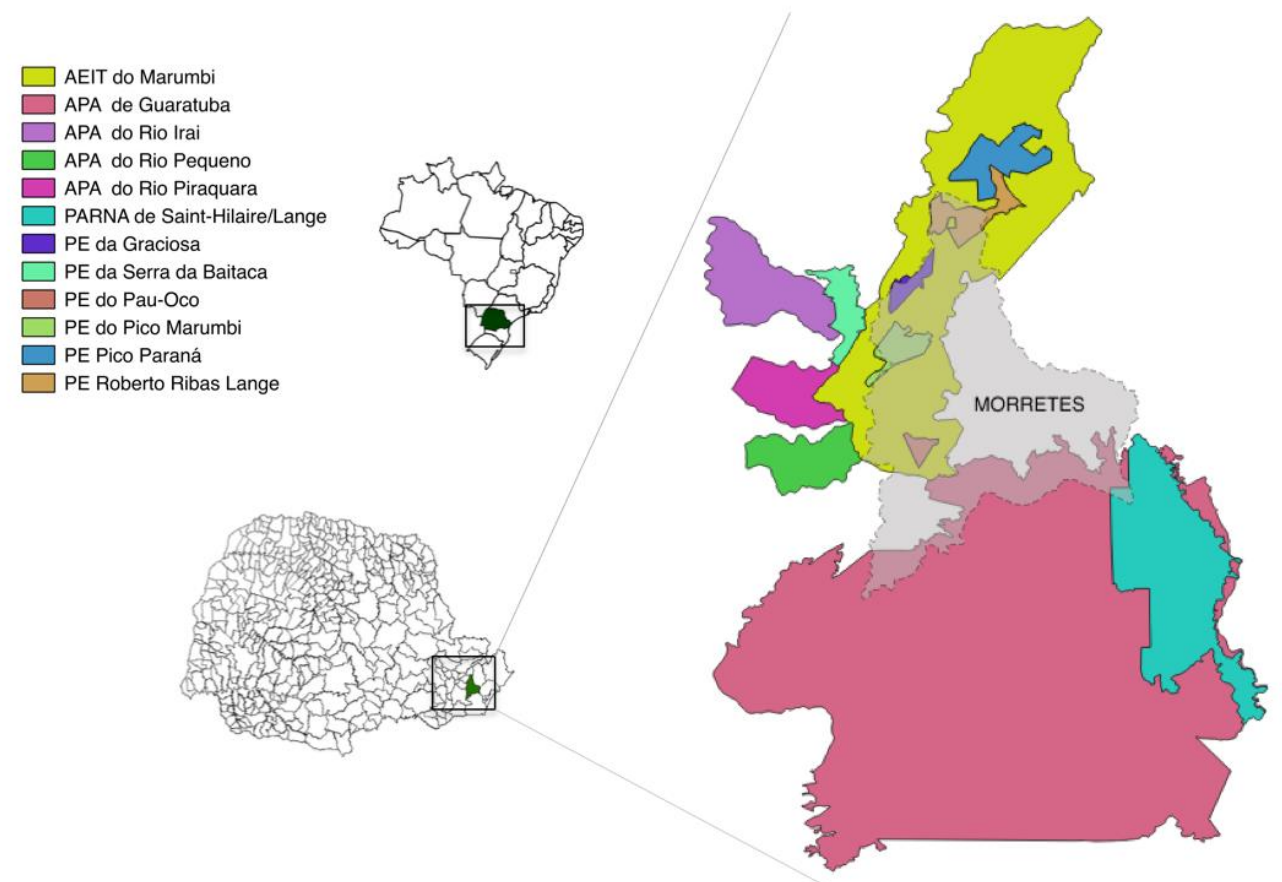

Figura 1: Localização da área estudo e das Unidades de Conservação parcial ou totalmente inseridas no Município de Morretes. Fonte: ITCG, 2013 (modificado). 


\section{Avaliação da Percepção Ambiental}

A caracterização da percepção da população de Morretes quanto às florestas e aos animais se deu através de entrevista com moradores das áreas urbana e rural, totalizando 20 indivíduos de cada grupo. Foram consideradas como zonas rurais aquelas que apresentavam atividade agropastoril e estavam afastadas do centro da cidade até $5 \mathrm{~km}$. Os entrevistados de ambos os sexos, maiores de 18 anos, alfabetizados ou não, foram abordados aleatoriamente. Excluiu-se da amostra acadêmicos ou graduados de Biologia e professores da área de Ciências.

O instrumento de avaliação elaborado para este estudo possuiu questões abertas $(\mathrm{N}=4)$, semi-estruturadas $(\mathrm{N}=18)$, não mutuamente excludentes e três delas relativas à atribuição de pontuação de 0 a 10 para graus de incômodo e de responsabilidade. As questões abordaram caracterização da amostra $(\mathrm{N}=6)$, percepção das áreas verdes $(\mathrm{N}=5)$, animais (insetos e mamíferos) $(\mathrm{N}=13)$ e responsabilidades $(\mathrm{N}=5)$. Mamíferos e insetos foram tratados separadamente devido à relação tradicional e antagônica estabelecida culturalmente. Simultaneamente ao formulário, imagens dos animais registrados na região foram apresentadas para reconhecimento.

As entrevistas foram realizadas de setembro a outubro de 2010 em residências e comércios após a explicação do objetivo, da importância do estudo para a conservação, direcionamento de programas de educação ambiental e da assinatura do Termo de Consentimento Livre e Esclarecido, o qual foi arquivado no Laboratório Núcleo de Estudos do Comportamento Animal PUCPR. O presente estudo teve aval do Comitê de Ética em Pesquisa da PUCPR ( $n^{\circ}$. 348590).

Os dados foram transcritos em planilha eletrônica e analisados qualitativamente de acordo com as escalas de valorização da biodiversidade de Kellert (1996): a) Utilitarista: prioriza o valor de uso da biodiversidade; b) Estética: prioriza valores estéticos; c) Humanista: os seres são dotados de características humanas; d) Simbólica: seres vivos como símbolo da linguagem; e) Negativista: aversão, medo, nojo e incomodo; e) Dominadora: domínio e controle das espécies; f) Ecologista: valor ecológico; g) Moralista: oposição a maus tratos e crueldades e h) Naturalista: espécies valorizadas em seus ambientes naturais. As respostas abertas foram analisadas após elaboração dos indicadores para fundamentação da interpretação, cujas informações foram codificadas e categorizadas tematicamente. Esta classificação dos elementos teve base em suas semelhanças e após reagrupamento, analisadas segundo os princípios da análise de conteúdo de Bardin (1994). Os resultados quantitativos das respostas categóricas foram comparados através do teste do qui-quadrado e as questões de atribuição de valores para o grau de incômodo e responsabilidades através dos testes não paramétricos Kruskall-Wallis e Mann-Whitney.

revista brasileira educação ambiental 


\section{Resultados}

Os entrevistados foram predominantemente do sexo feminino (rural: 65\% e urbano: $85 \%$ ), possuíam ensino fundamental (rural: $30 \%$ e urbano: $25 \%$ ) e médio (rural: $45 \%$ e urbano: $55 \%$ ) em detrimento do superior (rural e urbano: $20 \%$ ) e analfabetismo (rural: $5 \%$ ), correlacionados à 14 profissões na área rural (donas de casa: 25\%) e 12 na urbana (donas de casa: 35\%). A maioria dos entrevistados residia no local há mais de 15 anos (rural: $80 \%$ e urbano: $85 \%$ ).

As áreas florestais foram percebidas positivamente e desejadas próximas às residências, contudo foi possível identificar valoração estética e ecologista mais evidente nos moradores urbanos ao relacionarem-nas com a conservação, e utilitarista nos rurais ao indicarem a possibilidade da exploração econômica pelo ecoturismo (Tabela 1). A maioria dos entrevistados não demonstrou percepção evidente dos malefícios das áreas verdes, associando à rigidez das leis ambientais e às doenças na área urbana, e ao prejuízo na produção agropecuária na rural. Os animais silvestres foram relacionados com valoração ecologista, sendo as maiores frequências de visão negativista, atribuída aos moradores rurais e relacionando-as a prejuízos econômicos (Tabela 1).

Os mamíferos foram definidos principalmente pelas características comportamentais e citação de exemplos, sendo características morfológicas e status de conservação mais utilizados pelos moradores urbanos e desconhecimento da resposta pelos rurais. Os insetos foram conceituados principalmente com exemplos, categorizados como incômodos pelos habitantes rurais e através de suas características morfológicas e malefícios pelos urbanos. A importância dos mamíferos e insetos representou maior valoração ecológica do que utilitarista. Entretanto, os malefícios dos insetos foram mais relacionados às doenças e dos mamíferos à sujeira, sendo a correlação com doenças mais pontuadas pelos moradores urbanos (Tabela 2). 
Tabela 1: Frequência relativa das respostas relativas a cada pergunta com respeito à percepção das áreas verdes para o total e especificamente para moradores rurais e urbanos.

Os valores absolutos foram comparados através do teste do qui-quadrado sendo os significativamente diferentes $(\mathrm{P}<0,05)$ acompanhados do asterisco $\left({ }^{*}\right)$.

\begin{tabular}{|c|c|c|c|c|c|c|c|}
\hline & & Total & $x^{2}$ & Rural & $x^{2}$ & Urbano & $x^{2}$ \\
\hline \multirow{3}{*}{ 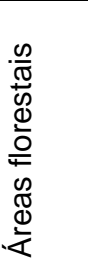 } & $\begin{array}{l}\text { Positiva, quanto mais perto da minha casa, } \\
\text { melhor. }\end{array}$ & $77,5 \%$ & * & $75 \%$ & * & $80 \%$ & * \\
\hline & $\begin{array}{l}\text { Positiva, contando que longe da minha } \\
\text { casa. }\end{array}$ & $20 \%$ & & $25 \%$ & & $15 \%$ & \\
\hline & $\begin{array}{l}\text { Negativa, pois limita o crescimento do } \\
\text { município. }\end{array}$ & $2,5 \%$ & & 0 & & $5 \%$ & \\
\hline \multirow{8}{*}{ 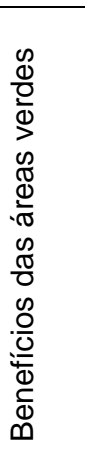 } & Ecoturismo & $32 \%$ & * & $44 \%$ & * & $22,5 \%$ & \\
\hline & Beleza & $20 \%$ & & $22,2 \%$ & & $19,3 \%$ & \\
\hline & Equilíbrio do ecossistema & $17 \%$ & & $7,4 \%$ & & $25,8 \%$ & * \\
\hline & Manutenção do clima & $15 \%$ & & $11,1 \%$ & & $19,3 \%$ & \\
\hline & Possibilidade de renda & $6,9 \%$ & & $7,4 \%$ & & $6,4 \%$ & \\
\hline & Outro & $1,7 \%$ & & $3,7 \%$ & & 0 & \\
\hline & Não vê benefícios & $1,7 \%$ & & $3,7 \%$ & & 0 & \\
\hline & Não soube responder & $3,4 \%$ & & 0 & & $6,4 \%$ & \\
\hline \multirow{6}{*}{ 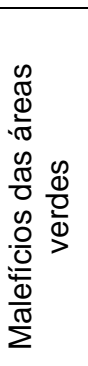 } & Não vê malefícios & $56 \%$ & * & $57 \%$ & * & $56 \%$ & * \\
\hline & Rigidez da legislação ambiental & $13 \%$ & & $9,5 \%$ & & $16 \%$ & \\
\hline & Doenças ocasionadas por animais & $13 \%$ & & $9,5 \%$ & & $16 \%$ & \\
\hline & Prejuízo na produção agrícola e de animais & $6,5 \%$ & & $14,3 \%$ & & 0 & \\
\hline & $\begin{array}{l}\text { Limitação na expansão do território do } \\
\text { município }\end{array}$ & $6,5 \%$ & & 0 & & $12 \%$ & \\
\hline & Proximidade de animais silvestres & $4,3 \%$ & & $9,5 \%$ & & 0 & \\
\hline \multirow{7}{*}{ 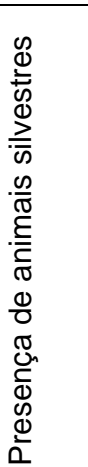 } & Positivo pela manutenção do ecossistema & $22,5 \%$ & & $25 \%$ & & $20 \%$ & \\
\hline & $\begin{array}{l}\text { Positivo pela polinização e dispersão de } \\
\text { sementes }\end{array}$ & $22,5 \%$ & & $20 \%$ & & $25 \%$ & \\
\hline & Negativo pela proliferação de doenças & $20 \%$ & & $30 \%$ & & $10 \%$ & \\
\hline & Positivo pela atração turística & $17,5 \%$ & & $15 \%$ & & $20 \%$ & \\
\hline & $\begin{array}{l}\text { Negativo pelos prejuízos na produção } \\
\text { agrícola e criação }\end{array}$ & $7,5 \%$ & & $5 \%$ & & $10 \%$ & \\
\hline & Positivo pela possibilidade de caça & $5 \%$ & & $5 \%$ & & $5 \%$ & \\
\hline & Não soube responder & $5 \%$ & & $0 \%$ & & $10 \%$ & \\
\hline
\end{tabular}

Fonte: dados da pesquisa.

revista brasileira

educação ambiental 
Tabela 2: Frequência relativa das respostas às perguntas sobre percepção de mamíferos e insetos total e para moradores rurais e urbanos. Os valores absolutos foram comparados através do teste do qui-quadrado sendo os valores significativamente diferentes $(P<0,05)$ acompanhados do asterisco $\left({ }^{*}\right)$.

\begin{tabular}{|c|c|c|c|c|c|c|c|c|}
\hline & \multicolumn{4}{|c|}{ Mamíferos } & \multicolumn{4}{|c|}{ Insetos } \\
\hline & Respostas & Total & Rural & Urbano & Respostas & Total & Rural & Urbano \\
\hline \multirow{5}{*}{ 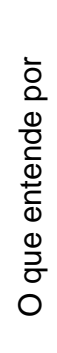 } & $\begin{array}{l}\text { Aqueles que } \\
\text { mamam }\end{array}$ & $40 \%{ }^{*}$ & $40 \%$ & $40 \%$ & Citam exemplos & $55 \%{ }^{*}$ & $75 \%{ }^{*}$ & $35 \%$ \\
\hline & Citam exemplos & $22,5 \%$ & $35 \%$ & $10 \%$ & Incomodam & $17,5 \%$ & 0 & $35 \%$ \\
\hline & $\begin{array}{l}\text { Características } \\
\text { morfológicas }\end{array}$ & $12,5 \%$ & 0 & $25 \%$ & São maléficos & $17,5 \%$ & $15 \%$ & $20 \%$ \\
\hline & $\begin{array}{l}\text { Animais em } \\
\text { extinção }\end{array}$ & $10 \%$ & 0 & $20 \%$ & $\begin{array}{l}\text { Características } \\
\text { morfológicas }\end{array}$ & $7,5 \%$ & 0 & $35 \%$ \\
\hline & $\begin{array}{l}\text { Não soube } \\
\text { responder }\end{array}$ & $15 \%$ & $25 \%$ & $5 \%$ & $\begin{array}{l}\text { Pode ser ruim } \\
\text { ou bom }\end{array}$ & $2,5 \%$ & $5 \%$ & 0 \\
\hline \multirow{6}{*}{ 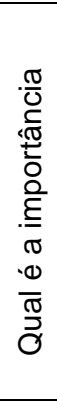 } & $\begin{array}{l}\text { Equilíbrio cadeia } \\
\text { alimentar }\end{array}$ & $32,5 \%$ & $45 \%$ & $20 \%$ & $\begin{array}{l}\text { Equilíbrio cadeia } \\
\text { alimentar }\end{array}$ & $40,4 \%{ }^{*}$ & $44 \% *$ & $36,4 \% *$ \\
\hline & $\begin{array}{l}\text { Manutenção das } \\
\text { florestas }\end{array}$ & $35 \%$ & $35 \%$ & $35 \%$ & $\begin{array}{l}\text { Manutenção das } \\
\text { florestas }\end{array}$ & $14,9 \%$ & $30 \%$ & $9 \%$ \\
\hline & Caça & $5 \%$ & 0 & $10 \%$ & Reciclagem & $8,5 \%$ & $8 \%$ & $9 \%$ \\
\hline & Atração turística & $15 \%$ & $20 \%$ & $10 \%$ & $\begin{array}{l}\text { Cura de } \\
\text { doenças }\end{array}$ & $6,4 \%$ & $4 \%$ & $9 \%$ \\
\hline & Não tem & $7,5 \%$ & 0 & $15 \%$ & Não tem & $17 \%$ & $24 \%$ & $9 \%$ \\
\hline & $\begin{array}{l}\text { Nao soube } \\
\text { responder }\end{array}$ & $5 \%$ & 0 & $10 \%$ & $\begin{array}{l}\text { Näo soube } \\
\text { responder }\end{array}$ & $12,7 \%$ & 0 & $27,3 \%$ \\
\hline \multirow{9}{*}{ 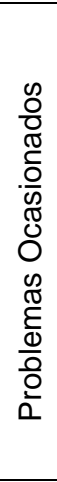 } & Sujeira & $24 \% \%^{*}$ & $25,9 \%{ }^{*}$ & $22,6 \%{ }^{*}$ & Sujeira & $16,7 \%$ & $13,8 \%$ & $19,4 \%$ \\
\hline & Barulho & $15,5 \%$ & $14,8 \%$ & $16,1 \%$ & Barulho & $15,0 \%$ & $13,8 \%$ & $16,1 \%$ \\
\hline & $\begin{array}{l}\text { Agricultura e } \\
\text { criação }\end{array}$ & $10,3 \%$ & $14,8 \%$ & $6,5 \%$ & $\begin{array}{l}\text { Agricultura e } \\
\text { criação }\end{array}$ & $11,7 \%$ & $13,8 \%$ & $9,7 \%$ \\
\hline & $\begin{array}{l}\text { Perigos de } \\
\text { ataques }\end{array}$ & $5,2 \%$ & $3,7 \%$ & $6,5 \%$ & $\begin{array}{l}\text { Perigos de } \\
\text { ataques }\end{array}$ & $5,0 \%$ & $3,4 \%$ & $6,5 \%$ \\
\hline & Doenças & $13,8 \%$ & $7,4 \%$ & $19,4 \%$ & Doenças & $33,3 \% *$ & $27,6 \%$ & $38,7 \% *$ \\
\hline & Saúde pública & $8,6 \%$ & $3,7 \%$ & $12,9 \%$ & Saúde pública & $8,3 \%$ & $10,3 \%$ & $6,5 \%$ \\
\hline & $\begin{array}{l}\text { Não souberam } \\
\text { responder }\end{array}$ & $17,2 \%$ & $22,2 \%$ & $12,9 \%$ & $\begin{array}{l}\text { Não souberam } \\
\text { responder }\end{array}$ & $10 \%$ & $17,2 \%$ & $3,2 \%$ \\
\hline & Deterioração & $3,4 \%$ & $3,7 \%$ & $3,2 \%$ & Deterioração & - & - & - \\
\hline & Outro & $1,7 \%$ & $3,7 \%$ & 0 & Outro & - & - & - \\
\hline \multirow{6}{*}{ 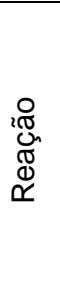 } & Nada & & & & Outro & $27,5 \%$ & $15 \%$ & $40 \%^{*}$ \\
\hline & Elimina & & & & Nada & $25 \%$ & $20 \%$ & $30 \%$ \\
\hline & Tem nojo & & & & Tem nojo & $20 \%$ & $20 \%$ & $20 \%$ \\
\hline & Tem medo & & & & Tem medo & $15 \%$ & $25 \%$ & $5 \%$ \\
\hline & $\begin{array}{l}\text { Relaciona com } \\
\text { sujeira }\end{array}$ & & & & $\begin{array}{l}\text { Relaciona com } \\
\text { sujeira }\end{array}$ & $5 \%$ & $10 \%$ & 0 \\
\hline & Gosta & & & & Gosta & $7,5 \%$ & $10 \%$ & $5 \%$ \\
\hline \multirow{5}{*}{ 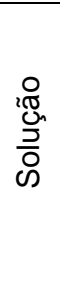 } & $\begin{array}{l}\text { Conscientizar a } \\
\text { população }\end{array}$ & $60 \%{ }^{*}$ & $70 \%{ }^{*}$ & $50 \% *$ & & & & \\
\hline & Eliminação & $15 \%$ & $15 \%$ & $15 \%$ & & & & \\
\hline & Translocação & $12,5 \%$ & $5 \%$ & $20 \%$ & & & & \\
\hline & $\begin{array}{l}\text { Nao soube } \\
\text { responder }\end{array}$ & $12,5 \%$ & $10 \%$ & $15 \%$ & & & & \\
\hline & Prefere afastado & $52,5 \%$ & $40 \%$ & $65 \%$ & Prefere afastado & $55 \%$ & $50 \%$ & $60 \%$ \\
\hline
\end{tabular}

Fonte: dados da pesquisa. 
Os mamíferos mais citados foram morcego, rato e tatu, sendo os problemas relacionados principalmente com rato, morcego, cachorro doméstico e gambá (Figura 2). Os insetos mais percebidos foram baratas, piolhos, abelhas, gafanhotos, pulga e lagarta. Animais como piolho de cobra, aranha, caramujo, escorpião, cobra, sapo, rato, minhoca e lagartixa também foram categorizados como insetos. Dos animais percebidos como insetos, apenas barata, abelha e lagarta foram considerados como problemas, seguidos de outros insetos como mosca, mosquito e formiga que não estavam inclusos no questionamento 'percebido' (Figura 3). Contudo, o grau de incômodo atribuído aos insetos e aos mamíferos diferiu entre os moradores rurais e urbanos, sendo ratos, formigas, cachorro-do-mato e gambá mais proeminentes nos urbanos (Figura 4).

A maioria dos entrevistados percebeu pouca degradação ambiental e consideram as mudanças nas políticas ambientais boas. No entanto, enquanto os moradores rurais acreditam que devam ser realizadas intervenções positivas, direcionando as responsabilidades da conservação para governo, prefeitura e população, os urbanos preferem a manutenção do ambiente intocado, atribuindo as responsabilidades para órgãos governamentais (Tabela 3). Ambos os grupos concordam com a importância da educação ambiental dentro do contexto.

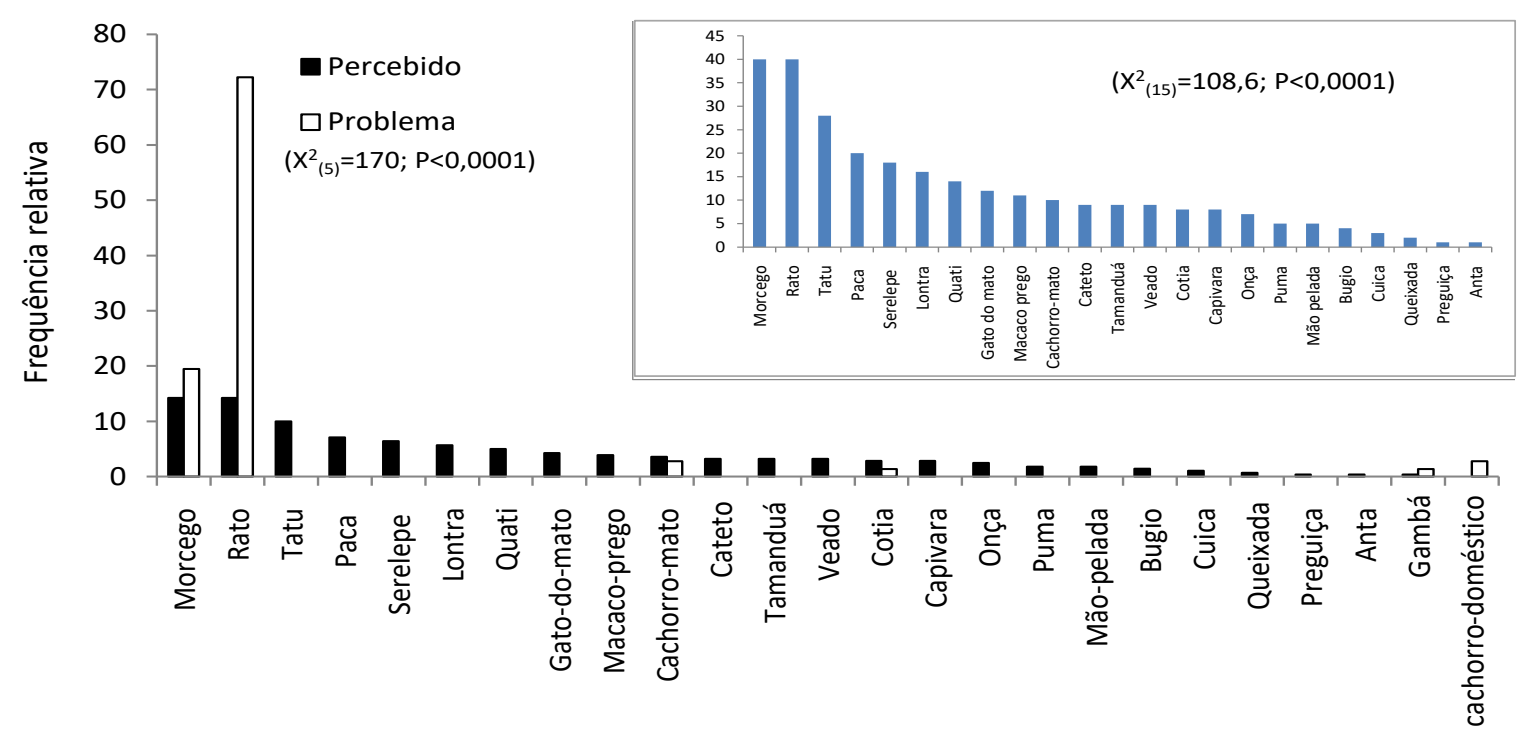

Figura 2: Frequência relativa de mamíferos percebidos pela população rural e urbana de Morretes (quadro menor) e comparação entre a frequência de registros percebidos e relacionados à problemas.

Fonte: dados da pesquisa. 


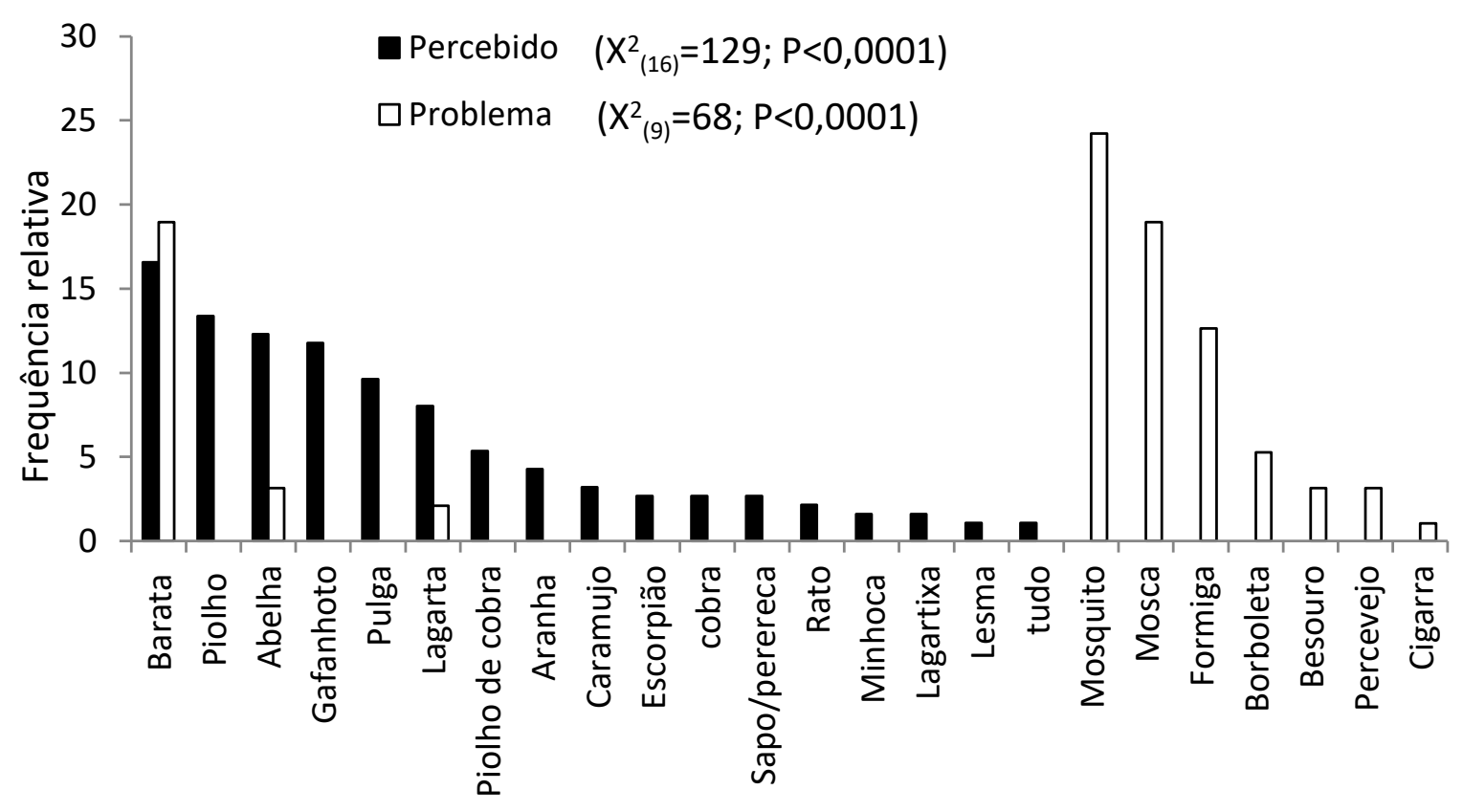

Figura 3: Frequência relativa de insetos percebidos pela população rural e urbana de Morretes e dos relacionados a problemas.

Fonte: dados da pesquisa.

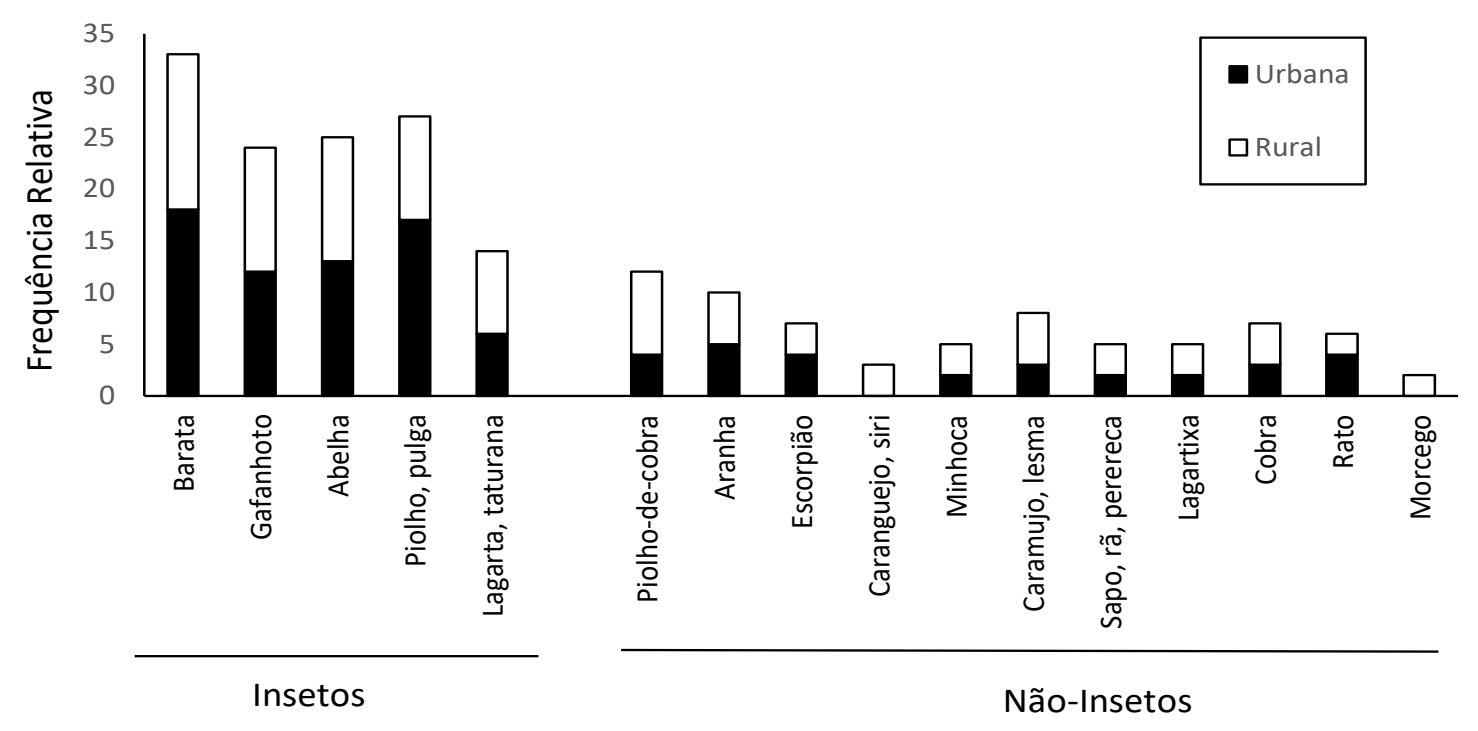

Figura 4: Frequência relativa de citações para os animais que relacionam ser ou não insetos. Os valores absolutos foram comparados entre os entrevistados da área rural e urbana através do teste do qui-quadrado, porém nenhuma diferença foi significativa $(P<0,05)$.

Fonte: dados da pesquisa 
Tabela 3: Frequência relativa das respostas às perguntas sobre percepção das ações necessárias para total e especificamente para moradores rurais e urbanos. Os valores absolutos foram comparados através do teste do qui-quadrado sendo os valores significativamente diferentes $(\mathrm{P}<0,05)$ acompanhados do asterisco $\left({ }^{*}\right)$.

\begin{tabular}{|c|c|c|c|c|c|c|c|}
\hline & & Total & $x^{2}$ & Rural & $\mathrm{X}^{2}$ & Urbano & $x^{2}$ \\
\hline \multirow{4}{*}{ 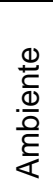 } & Pouco degradado & $50 \%$ & * & $45 \%$ & * & $55 \%$ & * \\
\hline & Bem conservado & $32,5 \%$ & & $30 \%$ & & $35 \%$ & \\
\hline & Muito degradado & $12,5 \%$ & & $20 \%$ & & $5 \%$ & \\
\hline & Não soube responder & $5 \%$ & & $5 \%$ & & $5 \%$ & \\
\hline \multirow{6}{*}{ 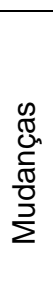 } & Boas & $62,5 \%$ & * & $60 \%$ & * & $65 \%$ & * \\
\hline & Ruins & $20 \%$ & & $20 \%$ & & $20 \%$ & \\
\hline & Inexistentes & $10 \%$ & & $10 \%$ & & $10 \%$ & \\
\hline & Péssimas & $2,5 \%$ & & $5 \%$ & & 0 & \\
\hline & Ótimas & $2,5 \%$ & & $5 \%$ & & 0 & \\
\hline & Não soube responder & $2,5 \%$ & & 0 & & $5 \%$ & \\
\hline \multirow{4}{*}{ 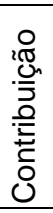 } & Interferindo positivamente & $37,5 \%$ & & $50 \%$ & * & $25 \%$ & \\
\hline & Não interferindo no meio ambiente & $35 \%$ & & $10 \%$ & & $60 \%$ & * \\
\hline & Interferindo o mínimo possível & $25 \%$ & & $40 \%$ & & $10 \%$ & \\
\hline & Não soube responder & $2,5 \%$ & & 0 & & $5 \%$ & \\
\hline \multirow{6}{*}{$\begin{array}{l}\frac{0}{0} \\
\frac{\pi}{0} \\
\frac{0}{\overline{0}} \\
\mathbb{0} \\
0 \\
\overline{0} \\
\frac{0}{0} \\
\mathbb{0} \\
\widetilde{0}\end{array}$} & IBAMA & $23,1 \%$ & * & $20,8 \%$ & & $26,3 \%$ & * \\
\hline & População & $20,9 \%$ & & $20,8 \%$ & & $21,1 \%$ & \\
\hline & Prefeitura & $18,7 \%$ & & $20,8 \%$ & & $15,8 \%$ & \\
\hline & ONG & $17,6 \%$ & & $18,9 \%$ & & $15,8 \%$ & \\
\hline & Governo & $11 \%$ & & $13,2 \%$ & & $7,9 \%$ & \\
\hline & Não sabe & $7,7 \%$ & & $3,8 \%$ & & $13,2 \%$ & \\
\hline \multirow[b]{2}{*}{ 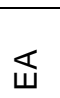 } & Acredita e considera de extrema importância & $90 \%$ & * & $90 \%$ & * & $90 \%$ & * \\
\hline & Acredita, mas não vê necessidade & $10 \%$ & & $10 \%$ & & $10 \%$ & \\
\hline
\end{tabular}

Fonte: dados da pesquisa.

\section{Discussão}

Os dados do presente estudo indicam diferenças na percepção e valorização ambiental entre moradores rurais e urbanos de Morretes, as quais devem ser levadas em consideração nas intervenções na comunidade. Devese considerar que a relação homem/ambiente e a consequente compreensão de responsabilidade são intermediadas por parâmetros pautados em interesses e conceitos que diferem com a categoria profissional, social e econômica na qual se insere, ainda que compartilhem um mesmo modelo cultural. Cada indivíduo carrega leitura ambiental própria, e caso seja discrepante com as necessidades reais, os modelos de relacionamento com a natureza deverão ser reorientados (SOUZA; SANTOS, 2010), destacando-se a avaliação da percepção ambiental quanto técnica multidisciplinar, interligando a psicologia, geografia, biologia, ecologia, etologia, sociologia e antropologia com intuito de compreender a relação comunidade/ambiente através das expectativas, 
satisfações e fatores determinantes do bem-estar biopsicossocial (QUADROS; FREI, 2009). Assim, o envolvimento da população local é um elemento importante e necessário na incorporação de estratégias de conservação para que adquiram capacidade de formular e alcançar os seus próprios objetivos de desenvolvimento em conformidade com a preservação (PRIMACK; RODRIGUES, 2001).

A percepção ambiental constitui-se numa importante ferramenta para a elaboração de programas de educação ambiental, os quais têm recebido destaque nos últimos 20 anos, sendo responsável por subsidiar políticas públicas, planejamento e gestão ambiental já prevista pela UNESCO desde 1973 (FREITAS; RIBEIRO, 2007; OLIVEIRA; CORONA, 2008; QUADROS; FREI, 2009; SOUZA; SANTOS, 2010). Tuan (1980) afirma ainda que o estudo das percepções ambientais e necessidades dos diferentes atores sociais é extremamente importante para uma gestão eficaz, uma vez que os problemas ambientais são fundamentalmente problemas humanos, cuja resolução depende da motivação, valores e atitudes do indivíduo. De acordo com o autor, a percepção pode ser considerada resposta dos sentidos aos estímulos externos, bem como atividade proposital, cujos fatos podem ser registrados ou bloqueados. Já a atitude é postura cultural e tem estabilidade maior, pois é composta por uma longa sucessão de percepções (TUAN, 1980). No entanto, ressalva-se que essa percepção não deve permanecer apenas ao nível de categorização do conhecimento, mas também da avaliação dos parâmetros éticos exercidos ao se depararem com uma situação que poderá comprometer os interesses de outros sujeitos, sejam eles humanos, natureza ou gerações futuras.

Os moradores rurais e urbanos valorizaram as áreas naturais da região de Morretes, evidenciando que diferentes atores sociais visam a qualidade ambiental. Esta é caracterizada como conjunto de condições materiais, sociais e psicológicas que maximizam o bem-estar no local em que se insere, agregando valores, identidade e interpretações (QUADROS; FREI, 2009). Contudo, é importante conhecer as necessidades específicas de cada grupo, pois conciliar a produção de bens com a preservação ambiental é fundamental em áreas tradicionalmente agrícolas que passam a ser incorporadas pelas leis de proteção ambiental.

Embora diferentes segmentos sociais se preocupem em informar os riscos ambientais, caso não haja uma efetiva diminuição e exploração dos recursos naturais, as ações podem se constituir de processos lentos ou incompletos, tendo ainda, um caráter mais individual do que coletivo. Os problemas ambientais não devem ser discutidos apenas sob este ponto de vista, mas incluir também contextos sociais, concepção econômica, política e individual, tal como: genética, idade, estado nutricional e de saúde (AYACH et al. 2012). Desta forma, promove a resolução de conflitos através de planejamento da utilização sustentável dos recursos naturais, propostas educativas, políticas públicas e determinação das responsabilidades (SOUZA; SANTOS, 2010). Para tanto, se torna necessário conhecer as diferentes 
concepções ambientais, as quais no presente estudo evidenciam a valoração ecológica pela população urbana.

A construção de uma consciência coletiva quanto aos riscos socioambientais derivados da modernidade, deve ser orientada através de processos educativos que levem à compreensão dos problemas e à elaboração de estratégias para solucioná-los, conduzindo, desta forma, o cidadão a optar por atitudes sob ponto de vista individual e local que reflitam na operacionalização de projetos de interesse global que beneficiem a natureza, a economia e a justiça social (VILLAR et al. 2008). Logo, deve-se investir em estratégias que leve moradores rurais e urbanos a conciliarem interesses em comum mesmo com necessidades específicas.

Os moradores da área urbana de Morretes indicaram possuir valoração ecologista e estética da natureza e apoio à implementação de UCs para manejo e a preservação ambiental. Contudo, pontos conflitantes têm sido levantados pelas populações que vivem no entorno dos parques, tais como a rigidez das leis, as doenças e os prejuízos econômicos. Deve-se considerar que as áreas protegidas são importantes ferramentas para conservação da biodiversidade. A primeira tentativa brasileira de criação de área de proteção ambiental data de 1911, com a Reserva Florestal do Território do Acre (RYLANDS; BRANDON, 2005). Após muitos anos e alterações estruturais e legislativas, em 2000 a Lei 9.985 instituiu o Sistema Nacional de Unidades de Conservação (SNUC), objetivando normatizar a criação, implantação e UCs (BRASIL, 2014). As UCs devem contribuir no gerenciamento dos ambientes naturais; proteger espécies e características naturais; restaurar áreas degradadas; proteger recursos hídricos e demais recursos fundamentais para manutenção de populações tradicionais; promover e valorizar a atividade científica e a educação ambiental (BRASIL, 2014). Elas podem ser de Proteção Integral, permitindo apenas o uso indireto dos recursos naturais (Estação Ecológica, Reserva Biológica, Parque Nacional, Monumento Natural e Refúgio de Vida Silvestre) e de Uso Sustentável, a qual alia uso sustentável e conservação dos recursos naturais (Área de Proteção Ambiental, Área de Relevante Interesse Ecológico, Floresta Nacional, Reserva Extrativista, Reserva de Fauna, Reserva de Desenvolvimento Sustentável e Reserva Particular do Patrimônio Natural) (BRASIL, 2014).

A legislação rígida quanto ao uso de recursos naturais tradicionalmente incorporados na cultura dessas comunidades tem causado impactos sociais, econômicos e culturais. Martins (2011) realizou um estudo no entorno da APA Tinguá-lguaçu, destacando os conflitos de interesses conservacionistas e de exploração dos recursos naturais decorrente da diversidade de atores envolvidos na manutenção da reserva. Segundo o autor, se estes forem motivados mais por interesses naturalísticos do que sociais, podem acarretar em baixa identificação e distanciamento das ações. Isto se deve principalmente pela resistência à mudança de atitudes culturalmente enraizadas e eticamente aceitas, tais como: a caça, coleta de palmitos, recreação, rituais religiosos, 
domesticação e comércio da fauna (MARTINS, 2011). As políticas devem prever a inclusão social nos processos de gestão, considerando que o valor atribuído à diversidade biológica não é algo que deve ser imposto, mas sim incorporado aos sistemas de valores de cada cultura. Isto diminui as distâncias entre o cidadão e a natureza intocável estabelecida pelos sistemas de gestão preservacionistas (MARTINS, 2011). Por isso, é importante identificar a concepção ética da população antes, durante e após as intervenções. Até mesmo no presente estudo, a valoração ecológica da natureza identificada inicialmente foi substituída pela valoração estética e utilitarista no decorrer da entrevista, indicando um prévio posicionamento politicamente correto que não se sustentou.

Souza e Santos (2010) avaliaram a percepção de usuários de uma UC visando identificar abordagens antropocêntricas (utilização dos recursos naturais), globalizantes (relações recíprocas entre natureza e sociedade) e naturalistas (ambiente como natureza intocada). Os autores não encontraram diferenças entre os usuários que participaram ou não das atividades de educação ambiental. Este resultado foi interpretado como falha na abordagem educativa, pois embora tenha havido predomínio da visão naturalista, a manutenção do posicionamento antropocêntrico evidencia que os antigos paradigmas se mantêm mesmo diante de uma nova ética, que demanda a valorização da natureza pelo seu valor intrínseco e não instrumental.

Os moradores urbanos demonstraram desejo de mais áreas florestadas próximas às suas residências, fato que se constitui como um importante subsídio no incentivo da manutenção de remanescentes urbanos. Ressalva-se, porém, que embora haja mudanças na valoração de áreas verdes urbanas decorrentes de benefícios estéticos e de lazer (FERREIRA, 2005), estas podem tornar-se problemáticas na ausência de planejamento (RIBEIRO, 2009). Considerando-se que a promoção do bem-estar ético, ambiental e de plenitude urbana associa-se a indicadores de bem-estar individual, ambiental e econômico, a função do parque urbano se expande para aplicação de conceitos de sustentabilidade, conservação e qualidade de vida fisiológica e psicológica; diminuindo os impactos dos excessivos estímulos visuais, sonoros, odoríferos e térmicos (BRUN et al. 2010). Segundo Andrade et al. (2006), frequentadores do Jardim Botânico no Rio de Janeiro, sentem-se tranquilos e confortáveis por poderem admirar silenciosamente o verde e os animais, contudo os autores reforçam a necessidade de associar práticas de educação ambiental visando a manutenção, conservação e segurança do parque.

A valoração utilitarista das áreas naturais por habitantes rurais de Morretes (vinculada ao ecoturismo) evidencia a percepção das mesmas como alternativas na geração de renda, procedimento presente na região conhecida pela culinária típica e turismo rural (IPARDES, 2013). Muitos moradores do entorno de reservas percebem a implementação do turismo como benéfico, igualando-o em grau de importância à preservação e conservação (GONÇALVES; HOEFFEL, 2012). Contudo a articulação entre o poder público e a sociedade civil é fundamental. Embora o ecoturismo seja desejado para 
aumento de renda local através do uso sustentável dos recursos naturais, não é possível desvincular o conflito entre costumes e valores nativos e não nativos (PRADO, 2003), os quais agem como barreiras na aceitação de uma ideologia ambientalista. Segundo Irving (2003), o ecoturismo e o turismo ecológico (de natureza ou de aventura) são práticas recentes nas pautas das políticas públicas, resultado de pressões internacionais relativas às demandas de conservação ambiental e às alternativas sustentáveis para o desenvolvimento local, assim, rompendo com paradigmas dominantes como a expansão agrícola, industrialização e desmistificação do prejuízo das leis com relação à valoração e proteção das áreas verdes. Esse processo é visto como uma ressignificação dos espaços rurais, valoração do retorno à natureza e possibilidade de vivência de uma realidade idealizada. $O$ Brasil se destaca nesse cenário tendo em vista sua diversidade cultural e biológica, bem como a extensão da cobertura florestal (IRVING, 2003). Desta forma, a promoção do ecoturismo se apresenta como um meio de acrescentar valor aos recursos e não à produção, protegendo ecossistemas ameaçados ao favorecer receitas para povos locais (CHERNELA, 2002; RUDZEWICZ, 2014).

Embora os proprietários rurais de Morretes vislumbrem no ecoturismo a possibilidade de ampliação da renda familiar, Sousa et al. (2008) destacam algumas limitações reais como: infraestrutura das estradas, investimentos em recursos técnicos e financeiros, além capacitação sobre a atividade. Lobo (2008) ressalta os impactos decorrentes do ecoturismo na superação do limite de carga de visita; descaso e abuso dos visitantes que praticam o mau uso dos recursos naturais; compactação do solo e poluição; despreocupação com as condições de vida dos moradores locais e exposição de comunidades tradicionais às drogas, prostituição e consumismo desenfreado.

Mesmo partindo da hipótese que mamíferos e insetos são tratados distintamente pela população, ressalva-se que os termos taxonômicos não são usuais e precisam ser considerados em programas de conservação e educação ambiental. $O$ fato dos mamíferos terem sido relacionados aos seus nomes, evidencia apresentação da resposta esperada. Já a utilização de exemplos e o desconhecimento, mais frequente em habitantes rurais e como características morfológicas e status de conservação, em urbanos, pode inicialmente sugerir relação com acesso à informação. Porém, não houve diferença no grau de escolaridade e provavelmente não hajam diferenças substanciais no acesso a meios de comunicação, sugerindo que provavelmente isto esteja relacionado a vivência em mais programas de educação não formal nos centros urbanos.

A percepção dos moradores a respeito dos animais não só caracterizou a área de moradia com o grupo do animal, mas reforça a importância da pesquisa da percepção das comunidades no entorno de reservas, visando auxiliar no manejo e programas de educação ambiental. A união de conhecimentos científicos a saberes tradicionais tende a mitigar conflitos entre humano-animal com 0 resguardo da tradição histórico-cultural e 
aproveitamento dos recursos naturais (MESQUITA, 2004; BARBOSA; BARBOSA, 2011; GONÇALVES; HOEFFEL, 2012). Embora ambos os grupos tenham evidenciado valorização ecologista ao relacionar a importância dos mamíferos e insetos ao equilíbrio ecológico e manutenção das florestas, moradores urbanos tenderam a não atribuir importância, desconhecer ou relacionar à caça. Enquanto a visão utilitarista relacionada com ecoturismo, no rural, indicam pontos de abordagem relevante a programas de educação ambiental, fato destacado por Zakrzevski (2004) que ressalta a necessidade de reformulação dos atuais modelos de educação ambiental no campo. Dentre as concepções éticas intermediadoras da relação humano-animal, predominou o antropocentrismo, identificado também em outros estudos cujos estudantes do ensino médio, moradores do entorno do Parque Nacional Montanhas do Tumucumaque, justificam a proteção da biodiversidade apenas pelos benefícios diretos aos interesses do homem (ALMEIDA, 2011). Contudo, no presente estudo, principalmente na área urbana foi percebida também valoração ecologista tendendo ao fortalecimento da aplicação da ética ecocêntrica, resultado do longo convívio com as práticas conservacionistas. Em geral, as comunidades tradicionais tendem a apresentar visão antropocêntrica, como registrado por Barbosa e Barbosa (2011). Na região da caatinga, a comunidade definiu o termo "animal" usando critérios afetivos, utilitários e conceituais, sob diferentes dimensões (cognitiva, afetiva, ideológicas e etológicas) (BARBOSA; BARBOSA, 2011). A visão afetiva está relacionada à potencialidade de domesticação, a conservacionista utilitarista com o consumo e comercialização e a negativista à animais que ofereçam risco econômico, de saúde ou aversão. Por fim, o ecocentrismo, considera o valor intrínseco da natureza, revertendo em atitudes pró-ambientais mesmo diante de animais que conflitam com os humanos, ou que provoquem ameaça ou aversão (ALMEIDA, 2011).

Inicialmente, quando indagados pelas imagens de mamíferos da região, predominou animais como morcegos, ratos e tatus, cada um com representatividade de mais de $25 \%$ das respostas. Destes, o tatu se destacou pela relação utilitarista positiva, provavelmente relacionada à caça, artesanato e uso medicinal, como constatado em outras regiões brasileiras (RPPN Caraca, MG: MESQUITA, 2004; Piauí: NEGREIROS et al. 2010). Quando indagados sobre os malefícios associados aos mamíferos, destacou-se o rato e 0 morcego, sendo incluídos o cachorro doméstico, o cachorro-do-mato e o gambá. Os malefícios dos mamíferos se relacionaram a incômodos como barulho e sujeira, evidenciando visão antropocêntrica, sendo que os moradores rurais tenderam, em menor escala, relacionar o malefício com a agricultura e o urbano a ataques e doenças. Os programas de conservação de fauna encontram grandes empecilhos quando se trata de animais que causam risco à saúde humana, embora as espécies sinantrópicas sejam atraídas para as construções, gerando impacto em ambas as populações. Os ratos totalizaram $70 \%$ das referências aos malefícios, sendo mais proeminente no ambiente urbano, porém também tendem a buscar recursos em locais de armazenamento de alimentos nas propriedades rurais. Roedores exóticos de 
importância global, tais como: a ratazana de esgoto Rattus norvegicus (Berkenhout, 1769), o rato de telhado Rattus rattus (Linnaeus, 1758) e o camundongo Mus musculus (Linnaeus, 1758), geram problemas de saúde pública, destacando-se a Leptospirose (BRASIL, 2009). Ademais, os roedores silvestres, pertencentes principalmente à subfamília Sigmodontinae, podem transmitir hantavirose, tornando vulneráveis os moradores de áreas próximas a paióis, galpões, porões e sótãos de construções antigas, abandonadas ou próximas a ambientes silvestres (FERREIRA, 2003). Devido a isso, a população é orientada a evitar o contato com esses animais, bem como com outros reservatórios de zoonoses silvestres, tais como o gambá. Além de causar sujeira, estes animais podem contaminar com salmonela a água utilizada por humanos, animais ou na irrigação (CASAGRANDE et al. 2011), além de servir como reservatório de Leishmaniose (ALVES et al. 2009) e Trypanosoma sp. (COMINETTI, 2010). Obviamente o controle de reservatórios naturais do vírus não é prático e pode levar ao desequilíbrio ambiental. Ferreira (2003) considera que a eliminação desses animais nos ambientes antrópicos é possível e deve ser uma prática rotineira, com medidas simples que evitem a entrada nas construções e, caso necessário, se faça o extermínio. A mesma interpretação não se aplica aos morcegos, animais tradicionalmente rejeitados e evitados (BREDT, 1998); entretanto, apenas uma minoria das espécies é hematófaga e um maior veículo para zoonoses como a raiva. As espécies geralmente associadas às construções humanas são frugívoras ou insetívoras e buscam fontes alimentares ou refúgio (BREDT, 1998; REIS et al. 2007). Segundo Reis et al. (2007), uma sociedade esclarecida, como já evidenciada em inúmeros países, deve se preocupar com a conservação de espécies de quirópteros, já que possuem um importantíssimo papel na manutenção dos ecossistemas e ao mesmo tempo, são seriamente ameaçados por inseticidas, desmatamentos e superstições.

Os cães acompanham o ser humano há pelo menos 10 mil anos, um curto espaço de tempo que resultou em inúmeras raças e no estreitamento das relações entre as duas espécies, sejam elas de trabalho, entretenimento ou companhia. A relação entre o homem e o cão é de simbiose e inúmeros estudos tem mostrado a melhoria da qualidade de vida das pessoas (LOPES; SILVA, 2012). Por outro lado, assim como evidenciado no presente estudo, animais abandonados em centros urbanos têm historicamente causado sérios problemas de saúde pública e embora esse seja um problema de escala mundial, foram poucas as ações de sucesso (CAMPOS et al., 2007). O poder público tem procurado solucionar questões relacionadas a ataques (SILVA, 2009), acidentes de trânsito (VERÇOSA, 2013) e as tradicionais transmissões de zoonoses (KATIGARI; OLIVEIRA-SEQUEIRA, 2007). Contudo, a presença de cães asselvajados tem comprometido a fauna nativa no entorno de remanescentes florestais (GALETTI; SAZIMA, 2006), demandando intervenções urgentes para que o bem-estar de todos os sujeitos envolvidos sejam preservados. 
O risco de ataque de animais como felinos (puma, onça-pintada e gatodo-mato) e canídeos (cachorro-do-mato e cachorro doméstico) às criações de animais domésticos (bovinos, equinos e caprinos) também uma é realidade nos entornos de reservas naturais no Estado do Paraná (VIDOLIN et al. 2004). Estes animais demandam grandes territórios, incompatíveis com a maioria das UCs, necessitando assim, a elaboração de políticas públicas que garantam a conservação dos animais, sem descuidar da qualidade de vida humana. Além da sensibilização para a problemática, dados sobre o impacto socioeconômico desses carnívoros devem viabilizar a implantação de medidas compensatórias aos danos, através do mapeamento das condições favoráveis aos ataques, concomitantemente com práticas de manejo, como cercas elétricas, iluminação noturna e cincerros no gado. O diálogo promovido pela bioética ambiental considera a vulnerabilidade da integridade física, econômica e civil dos proprietários rurais diante dos animais silvestres, que também se veem vulneráveis diante da destruição do seu hábitat e diminuição de recursos.

Embora os entrevistados tenham indicado conhecer as leis, relacionando a rigidez legal como malefício de se viver no entorno das UCs, não foi evidenciada a indicação de que os animais silvestres eram usados para caça, alimentação, comercialização, medicina, estimação e/ou religião como no registrado por Negreiros et al. (2010). Contudo, é sabido que a prática é mantida por muitos moradores que consideram os aspectos culturais mais relevantes do que a legislação, causando problemas ambientais por falta de políticas públicas que conciliem práticas milenares com mudanças rápidas nos códigos de conduta, transformando assim a cultura em prática ilegal. Segundo Vidolin e Moura-Brito (1998), a caça de animais silvestres é comum em todo o Estado do Paraná, demandando a implementação de sistema de proteção planejado, intenso trabalho de educação ambiental e geração de alternativas de renda. A megadiversidade do Brasil, somada aos aspectos culturais, dificuldades nas políticas de fiscalização, educação e conscientização, estimulam um tráfico de 12 a 38 milhões de animais por ano, gerando de 10 a 20 bilhões de dólares anuais (NEGREIROS et al. 2010). Segundo Almeida (2011), o desejo de possuir animais selvagens como estimação, decorre da apreciação estética e recreacional de animais como macacos, cutias, jabutis, antas, araras, papagaios, preguiças, tatus e jiboias. Contudo, estudantes entrevistados indicam uma visão moralista correlacionada negativamente ao utilitarismo, condenando o abate desnecessário, principalmente de cutias, jaguatiricas e veados, bem como o tráfico de animais, tais como aves e macacos (ALMEIDA, 2011). Deve-se ressaltar que esses animais apresentam características comportamentais, ecológicas e sanitárias específicas, e que sua comercialização acarreta uma modificação extrema do seu meio natural, além do desenvolvimento de um comércio ilegal e cruel (REICHMANN et al. 2000).

A valoração ecológica inicialmente vinculada ao registro espontâneo, assim como os dados de Almeida (2011), se transfigurou para o antropocentrismo e utilitarismo quando indagados diretamente sobre os malefícios, reforçando a significação instrumentalista. Em ambos os casos, a visão negativista pareceu se relacionar com atitudes antiprotecionistas, 
demandando intervenções na mudança de percepção de alguns animais, bem como por possibilitar a descoberta de valores na fauna local que extrapolem os limites do pensamento utilitarista. Almeida (2011) ressalta que trabalhar a ética já nas séries iniciais do ensino formal é imprescindível, pois embora a mesma não tenha a pretensão de solucionar os problemas atrelados à crise ecológica, pode ser uma ferramenta que dialoga, cria pontos de reflexão e possibilita a construção de novos valores que contribuam para contenção da crescente e fatídica crise ambiental. Atrelado a isso, deve-se considerar o papel da mídia na formação da percepção da relação com os animais, e a utilização de diferentes canais de comunicação que explorem ferramentas e linguagens específicas para cada público. Embora a busca da sustentabilidade tenha como aliada a legislação e a criação de unidades de conservação, é imprescindível a educação ambiental.

A denominação taxonômica dos animais, tanto para mamíferos quanto para insetos, não correspondeu aos critérios científicos, sendo este fato relevante para as intervenções na comunidade. Assim como em diferentes culturas e tradições, os habitantes de Morretes referenciam a categoria etnotaxonômica "inseto" a outros animais, baseando-se na vivência pessoal e não acadêmica, apoiada nas informações repassadas culturalmente e pela mídia (ULYSSÉA et al. 2010; COSTA-NETO; PACHECO, 2004; NAVARIJOS; LOURDES, 2006). O afastamento da natureza tem tirado do homem a habilidade de diferenciar as espécies morfológica e funcionalmente, predominando uso de sensações emotivas, representações afetivas e categorização representacional, levando à "cultura do inseticida", ou seja, os animais incluídos nessa categoria devem ser eliminados (COSTA-NETO; PACHECO, 2004). Os insetos, espécies chave para a conservação através da manutenção dos ecossistemas, pela ciclagem de nutrientes, polinização, dispersão de sementes, manutenção do solo e cadeia alimentar (FISHER, 1998) são percebidos sob uma variedade de valores relacionados ao lúdico (cigarra, formiga, libélula, paquinha e vagalume), decorativo (borboleta, joaninha e libélula), alimentício (abelha), medicinal (abelha, barata, formiga, paquinha, aranhas, cobras, lagartixa e jacaré), folclórico (cigarra, gafanhoto, libélula: previsão tempo) e econômico (borboleta) (CONCONI et al. 1984; COSTA-NETO; RESENDE, 2004; ALVES, 2008; ULYSSÉA et al. 2010). A possível valoração ecológica inicial transfigurou em visão negativista, já que dos 15 grupos taxonômicos referidos como insetos, 10 deles são de outras ordens. Assim, miriápodes, aracnídeos, crustáceos, moluscos, anelídeos, anfíbios, répteis, morcegos e ratos despertaram sensações entomofóbicas como medo, desprezo, aversão, nojo e irritação (COSTA-NETO; PACHECO, 2004; COSTA-NETO; RESENDE, 2004; NAVARIJOS; LOURDES, 2006; ULYSSÉA et al. 2010; ALENCAR et al. 2012). Os insetos mais visualizados diferiram dos relacionados aos malefícios, sendo que moscas, mosquitos e baratas incomodaram mais habitantes rurais, e as formigas os habitantes urbanos. De fato, moscas, mosquitos, baratas e piolhos, por serem transmissores de zoonoses (PAPINI et al. 2009; ALMEIDA, 2011) e as abelhas 
pela intoxicação (OLIVEIRA et al. 2000), são categorizados como praga urbana, e os gafanhotos como praga agrícola (MAGALHÃES; LECOQ, 2006), sendo então alvos de controle. Essa questão é delicada, pois assim como o cidadão deve ser orientado para os perigos na propagação da praga, o controle sem orientação pode causar o impacto de espécies nativas, como o exemplo das abelhas nativas (ROCHA; ALENCAR, 2006). Costa-Neto e Pacheco (2004) ressaltam que, para se obter sucesso das intervenções na conservação, devese considerar fatores emocionais. Logo, através de aprendizagem baseada em estímulos sensoriais, é possível modificar a emoção e a maneira pela qual os objetos são percebidos, levando tanto à conservação quanto ao manejo daqueles que de fato trazem danos. Assim, atenção especial deve ser dada aos animais utilizados na zooterapêutica, a qual deve ser incluída nas políticas de sustentabilidade, além do incentivo a entomofagia, considerando a qualidade proteica de muitos insetos que podem ser usados para aliviar a fome e a desnutrição (CONCONI et al. 1984).

Os entrevistados evidenciaram visão otimista do ambiente, percebendo a corresponsabilidade de diferentes segmentos sociais e aceitando a educação ambiental como ferramenta para se atingir uma relação melhor com a natureza. Em geral, a relação estabelecida entre a população e as UCs caracteriza-se pela falta de consciência sobre sua importância, ausência de apoio na criação e manutenção, e nenhuma participação pública na administração dos recursos naturais. No entanto, a conservação efetiva dos recursos naturais a longo prazo, depende diretamente de apoio público, sem 0 qual esforços conservacionistas estão fadados ao fracasso (WELLS; BRANDON, 1992). $\mathrm{Na}$ América Latina, onde $86 \%$ dos parques nacionais possuem populações humanas (AMEND; AMEND, 1995), a participação das comunidades deveria ser prioritária em qualquer ação conservacionista (PADUA; TABANEZ, 1997). A bioética ambiental tem como princípio promover a reflexão de diferentes segmentos sociais a respeito de temas necessários e urgentes, viabilizar 0 diálogo entre os interesses pessoais e econômicos da comunidade com os interesses conservacionistas e apoiar as políticas na promoção do bem-estar de todos. A intervenção deve ocorrer através da educação ambiental, contudo, a transposição das reflexões teóricas e o elo entre a academia e a sociedade deve ser de forma consciente e programada, levando em consideração diferentes linguagens, percepções, interesses, experiência, idade, sexo, hábito alimentar e local de moradia (KELLERT; BERRY, 1982; SAUVÉ, 2005) para que sejam realizadas adequações das estratégias teórico-metodológicas (ALMEIDA, 2011).

O fato de a geração atual ser mais inclinada com as questões ambientais, por terem crescido em meio a debates ambientais e ativistas absolutistas alicerçando-se em princípios universais e empáticos às questões ambientais (KELLERT; BERRY, 1982; KNIGHT et al. 2004), é um ponto importante a ser considerado. Assim, a bioética ambiental não se propõe a solucionar problemas ecológicos, mas sim permitir uma ferramenta que dialoga, levanta pontos de reflexão e permite uma coparticipação na construção de valores e intervenções para contenção desses problemas. 


\section{Agradecimentos}

pesquisa.

Aos moradores do município de Morretes pela participação na

\section{Referências}

ALENCAR, J. B. R.; SILVA, E. F.; SANTOS, V. M.; SOARES, H. K. L.; LUCENA, R. F. P.; BRITO, C. H. Percepção e uso de "insetos" em duas comunidades rurais no semiárido do estado da Paraíba. BIOFAR Revista de Biologia e Farmácia, v. 9, p. 72-91, 2012.

ALMEIDA, P. G. Os mosquitos (Diptera, Culicidae) e a sua importância médica em Portugal: Desafios para o Século XXI. Acta Médica Portuguesa, v. 24, n. 6, p. 961-974, 2011.

ALVES, L. C. R. A urgência de uma nova ética ambiental. Polymatheia Revista de Filosofia, v. 4, n. 6, p. 237-249, 2008.

ALVES, M. F.; BUZZETI, W. A. S.; PAIXÃO, M.; TENÓRIO, M.; QUINTAL, A. Levantamento de Leishmaniose Visceral em marsupiais Didelphis albiventris capturados no centro de conservação da fauna silvestre no município de llha Solteira, São Paulo, Brasil. XXI Congresso de Iniciação Científica, UNESP, Bauru, 2009.

AMEND, S.; AMEND, T. Inhabitants in National Parks: an unsolvable contradiction? In: AMEND, S.; AMEND, T. National Parks without People? The South American Experience. Equador, IUCN Parques Nacionales y Conservación Ambiental, n. 5, 1995.

ANDRADE, B.R.D.; LIMA, F.H.; MARCONDES, G. A.; CANHAS, I.N.; FONSECA, M.T.; BARBOSA, S.B.L.; RIBEIRO, W.C.; LEITE, E.B. Ecossistemas e áreas verdes urbanas - um estudo de percepção ambiental no Parque Julien Rien, região centro-sul de Belo Horizonte. Revistas Eletrônicas PUCMG, 2006.

ARRUDA, R. "Populações tradicionais" e a proteção dos recursos naturais em unidades de conservação. Ambiente \& Sociedade, v. 2, n.5, p.79-92, 1999.

AYACH, L.R.; GUIMARÃES, S.T.L.; CAPPI, N.; AYACH, C. Saúde, saneamento e percepção de riscos ambientais urbanos. Caderno de Geografia, v. 22; n. 37, p.47-64, 2012.

BARBOSA, J.A.A.; BARBOSA, R.K.V.C. Percepção de moradores do semiárido paraibano sobre a diversidade e relevância da fauna em duas

revista brasileira

educação ambiental 
comunidades rurais. Revista de Biologia e Ciências da Terra, v. 1, p. 123133, 2011.

BARDIN, L. Análise de Conteúdo. Lisboa, Edições 70, 1994.

BASTARZ, C. Análise da preferência da paisagem do município de Morretes, Paraná como subsídio ao planejamento do turismo. 2009. 122 f. Dissertação (Mestrado em Engenharia Florestal), Setor de Ciências Agrárias, Universidade Federal do Paraná.

BRASIL. Ministério do Meio Ambiente. Sistema Nacional de Unidades de Conservação. Brasília, DF. Disponível em: <http://www.mma.gov.br/areasprotegidas/unidades-de-conservacao >. Acesso em: 20 fev. 2014.

BRASIL. Ministério da Saúde. Vigilância em saúde: zoonoses. Textos Básicos de Saúde, Cadernos de Atenção Básica, Brasília, n. 22, 2009.

BREDT, A. Morcegos em áreas urbanas e rurais: Manual de manejo e controle. Fundação Nacional de Saúde, Brasília, 2ª edição, 1998.

BRUN, F.G.K.; DOBBERT, L.Y.; SERVOLO-FILHO, H.J.; ZAIA, H.B.A.; SILVAFILHO, D.F. Percepção dos usuários em relação ao conforto ambiental de duas áreas verdes de Piracicaba, SP. REVSBAU, v. 5, n. 3, p. 59-81, 2010.

CAMPOS, C.B.; ESTEVES, C.F.; FERRAZ, K.M.P.B.; GRAWSHAW, P.G.; VERDADE, L. M. Diet of free-ranging cats and dogs in a suburban and rural environment, South eastern Brazil. Journal of Zoology, v. 273, p. 14-20, 2007.

CARVALHO, I.C.M. Educação ambiental: a formação do sujeito ecológico. São Paulo, Ed. Cortez, 2 ed, 2004.

CASAGRANDE, R.A., LOPES, L.F.L.; REIS, E.M.; RODRIGUES, D. P.; MATUSHIMAI, E. R. Isolamento de Salmonella enterica em gambás (Didelphis aurita e Didelphis albiventris) do Estado de São Paulo, Brasil. Ciência Rural, v. 41, n. 3, p.492-496, 2011.

CHERNELA, J; ALI, A.; Fazlun, K.; VIV, S.; JAIRETH, H. Innovative governance of fisheries and ecotourism in community-based protected areas. Parks, v. 12, n. 2, p. 28-41, 2002.

COMINETTI, M. C. Infecção natural por Trypanosoma sp. em Triatoma sordida, Didelphis albiventris e Sus scrofa em comunidade rural de Mato Grosso Do Sul, Brasil. 2010. 98f. Dissertação (Mestrado em Doenças Infecciosas e Parasitárias) - Universidade Federal de Mato Grosso do Sul, Campo Grande.

CONCONI, J. R.E.; MORENO, J. M. P.; MAYAUDON, C. M.; VALDEZ, F. R.; PREZ, M. A.; PRADO, E. E.; RODRIGUEZ, H. B. Protein content of some edible insects in Mexico. Journal of Ethnobiology, v. 4, n. 1, p. 61-72, 1984.

COSTA-NETO, E.M.; PACHECO, J.M. A construção do domínio etnozoológico "inseto" pelos moradores do povoado de Pedra Branca, Santa Terezinha, Estado da Bahia. Acta Scientiarirum, v. 26, n.1, p. 81-90, 2004. 
COSTA-NETO, E.M.; RESENDE, J. J. A percepção de animais como "insetos" e sua utilização como recursos medicinais na cidade de Feira de Santana, Estado da Bahia, Brasil. Acta Scientiarium, v. 26, n.2, p. 143-149, 2004.

FERNANDES, R. S.; SOUZA, V.J.; PELISSARI, V.B.; FERNANDES, S.T. Uso da percepção ambiental como instrumento de gestão em aplicações ligadas às áreas educacional, social e ambiental. Anais do II Encontro da ANPPAS, Indaiatuba, v. 1, p. 1-20, 2004.

FERREIRA, A. D. Efeitos positivos gerados pelos parques urbanos: o caso do passeio público da cidade do Rio de Janeiro. 2005. 111f. Dissertação (Mestrado em Ciência Ambiental), Universidade Federal Fluminense.

FERREIRA, M. S. Hantaviroses. Revista da Sociedade Brasileira de Medicina Tropical, v. 33, n. 1, p. 81-96, 2003.

FISHER, B. L. Insect behavior and ecology in conservation: preserving functional species interactions. Annals of the Entomological Society of America, v. 91, n. 2, p. 155-158, 1998.

FREITAS, R.E.; RIBEIRO, K.C.C. Educação e percepção ambiental para a conservação do e meio ambiente na cidade Manaus: uma análise dos processos educacionais no centro municipal de educação infantil Eliakin Rufino. Revista Eletrônica Aboré, v. 3, p 1-17, 2007.

GALETTI, M.; SAZIMA, I. Impacto de cães ferais em um fragmento urbano de Floresta Atlântica no sudeste do Brasil. Natureza e Conservação, v. 4, n. 1, p. 58-63, 2006.

GONÇALVES, N. M.; HOEFFEL, J. L. M. Percepção ambiental sobre unidades de conservação: os conflitos em torno do Parque Estadual de Itapetinga - SP. Revista VITAS, v. 3, p. 1-15, 2012.

IAP - Instituto Ambiental do Paraná. Unidades de Conservação. Curitiba, 2014. Disponível em <http://www.uc.pr.gov.br/>. Acesso em: 20 fev. 2014.

IBGE - Instituto Brasileiro de Geografia e Estatística. Cidades: Morretes. Disponível em: <http://cod.ibge.gov.br/2378U>. Acesso em: 13 mar. 2014.

IPARDES - Instituto Paranaense de Desenvolvimento Econômico e Social. Diagnóstico Físico Ambiental da Serra do Mar - Área Sul, Curitiba, v.1, 1991. Disponível em: <http://www.ipardes.gov.br/webisis.docs/diag fisico serradomar 0491 v1.pdf>. Acesso em: 05 ago. 2013.

IPARDES - Instituto Paranaense de Desenvolvimento Econômico e Social. Caderno estatístico Município de Morretes, dez/2013. Disponível em: $<$ http://www.ipardes.gov.br/cadernos/Montapdf.php?Municipio=83350 >. Acesso em: 05 ago. 2013.

ITCG - Instituto de Terras, Cartografia e Geociências. Dados e informações geoespaciais temáticos. Disponível em: <http://www.itcg.pr.gov.br/>. Acesso em: 05 ago. 2013. 
IRVING, M. A. Transformação da realidade e percepção do ecoturismo no Brasil: refletindo sobre potencialidades e tendências. Territoris, n. 4, p. 111127, 2003.

KATAGIRI, S.; OLIVEIRA-SEQUEIRA, T.C.G. Zoonoses causadas por parasitas intestinais de cães e o problema do diagnóstico. Arquivos do Instituto Biológico, v. 74, n.2, p. 175-184, 2007.

KELLERT, S.R. The Value of Life. New York: Island Press, 1996.

KELLERT, S.R.; BERRY, J.K. Knowledge, affection and basic attitudes toward animals in American society. US Department of the Interior, Fish and Wildlife Service, 1982.

KNIGHT, S.; VRIJ, A.; CHERRYMAN, J.; NUNKOOSING, K. Attitudes towards animal use and belief in animal mind. Anthrozoös, v. 17, p. 43-62, 2004.

LEFF, E. Epistemologia Ambiental. São Paulo, Cortez Editora, 2001.

LEITE, D. C., DOURADO, T. M. F. A., MARTINS, A. L. L., DOURADO, J. C., OLIVEIRA, J. S., CARRIJO, A. G. Percepção ambiental em escolas rurais: subsídios para educação ambiental. Revista Brasileira de Educação Ambiental, v. 10, n. 3, p. 134-146, 2015.

LOBO, H.A.S. Ecoturismo e percepção de impactos socioambientais sob a ótica dos turistas no parque estadual turístico do Alto Ribeira - PETAR. Pesquisas em turismo e Paisagens Cársticas, v. 1, n. 1, p. 67-76, 2008.

LOPES, K. R.; SILVA, A. R. Considerações sobre a importância do cão doméstico (Canis lupus familiaris) dentro da sociedade humana. Acta Veterinária Brasilica, v. 6, n. 3, p.177-185, 2012.

MAGALHÃES, B. P.; LECOQ, M. Bioinseticida e gafanhotos-praga: Relatório final do projeto "Desenvolvimento de bioinseticidas para controle de gafanhotos-praga no Brasil". Brasília, Embrapa Recursos Genéticos e Biotecnologia, 2006.

MARIN, A. A.; OLIVEIRA, H. T.; COMAR, V. A educação ambiental num contexto de complexidade do campo teórico da percepção. Interciência, v. 28, n. 10, p. 616-619, 2003.

MARTINS, A.L.L. Lazer e área protegida: conflitos na busca de "emoções agradáveis". Ambiente e Sociedade, v. 14, n. 2, p. 51-67, 2011.

MESQUITA, E. D. S. Percepções e usos da fauna silvestre pelas comunidades humanas do entorno da reserva particular do patrimônio natural do Caraça, Catas Altas/Santa Barbara, MG. 2004. 92f. Dissertação (Mestrado em Zoologia de Vertebrados de Ambientes Impactados). Pontifícia Universidade Católica de Minas Gerais, Belo Horizonte.

NAVARIJOS, O.; LOURDES, M. Percepciones e importancia de los insectos em el ambito urbano de la ciuldad de Mexico, Mexico. Sitientibus Série Ciências Biológicas, v. 6, n. 4, p. 334-342, 2006. 
NEGREIROS, A. B.; SILVA, F. P.; LIMA, R. N. Percepção ambiental sobre a caça de animais silvestres: diferentes visões na cidade de Floriano-PI. V CONNEPI - Congresso de Pesquisa e Inovação da Rede Norte Nordeste de Educação Tecnológica, Maceió, 2010. Disponível em: $<$ http://congressos.ifal.edu.;br/index.php/connepi/CONNEPI2010/paper/viewFile /786/495>. Acesso em: 03 jun. 2013.

OLIVEIRA, F.A.; GUIMARÃES, J.V.; REIS, M.A.; TEIXEIRA, V.P.A. Acidente humano por picadas de abelhas africanizadas. Revista da Sociedade Brasileira de Medicina Tropical, v. 33, n. 4, p. 403-405, 2000.

OLIVEIRA, K. A.; CORONA, H. M. P. A percepção ambiental como ferramenta de propostas educativas e de políticas ambientais. Revista Científica ANAP Brasil, v. 1, n. 1, p. 53-72, 2008.

PADUA, S.M.; TABANEZ, M.F. Educação Ambiental: Caminhos trilhados no Brasil. Brasília, Ipê Instituto de Pesquisas Ecológicas, 1997.

PAPINI, S.; OLIVEIRA, J.L.; MAZZONI, A.; ANDRADE, M.I.O.; LUCHINI, L.C. Abundância e impacto do controle de pragas urbanas na região de uma subprefeitura do município de São Paulo. Hygeia Revista Brasileira de Geografia Médica e da Saúde, v. 5, n. 9, 2009.

POTTER, V. R. Bioethics: the science of survival. Perspectives in biology and medicine, v. 14, p. 173-153, 1970.

PRADO, R. M. As espécies exóticas somos nós: reflexão a propósito do ecoturismo na llha Grande. Horizontes antropológicos, v. 6, n. 20, p. 205224, 2003.

PRIMACK, R. B.; RODRIGUES, E. Biologia da Conservação. Londrina, Editora Vida, 2001.

QUADROS, L. S.; FREI, F. Percepção ambiental dos residentes da cidade de Assis-SP com relação à arborização viária da avenida Rui Barbosa. REVSBAU, v. 4, p. 16-34, 2009.

REICHMANN, M.L.A.B.; PINTO, H.B.F.; ARANTES, M.B.; SANTOS, M. B.; VIARO, O.; NUNES, V.F.P. Educação e Promoção da Saúde no Programa de Controle da Raiva. Instituto Pasteur, São Paulo, n. 5, 2000. Disponível em: $<$ http://www.saude.sp.gov.br/resources/instituto-pasteur/pdf/manuais/manual 0 5.pdf>. Acesso em: 15 fev. 2014.

REIS, N.R.; PERACCHI, A.L.; PEDRO, W.A.; LIMA, I.P. Morcegos do Brasil. 253 p. Londrina, 2007.

RIBEIRO, F. A. B. S. Arborização urbana em Uberlândia: percepção da população. Revista da Católica, v. 1, n.1, p. 224-237, 2009.

ROCHA, M.C.L.; ALENCAR, S. Efeitos dos agrotóxicos sobre as abelhas silvestres no Brasil: proposta metodológica de acompanhamento, IBAMA, Brasília, 2012.

revista brasileira

educação ambiental 
RUDZEWICZ, L. O ecoturismo como instrumento para a sustentabilidade de Unidades de Conservação. Ecoterra. Disponível em: $<$ http://www.ecoterrabrasil.com.br/home/index.php?pg=temas\&tipo=tema\&cd=1 97\#>. Acesso em: 15 fev. 2014.

RYLANDS, A. B.; BRANDON, K. Unidades de conservação brasileiras. Megadiversidade, v. 1, n. 1, p. 27-35, 2005.

SANTOS-FITA, D.; COSTA-NETO, E. M. As interações entre os seres humanos e os animais: a contribuição da etnozoologia. Biotemas, v. 20, n. 4, p. 99-110, 2007.

SAUVÉ, L. Educação Ambiental: possibilidades e limitações. Educação e Pesquisa, v. 31, n. 2, p. 317-322, 2005.

SILVA-FILHO, L.V.; BRAGA, M.C.B. Abordagem para o desenvolvimento de um questionário de percepção ambiental em uma bacia hidrográfica urbana. $3^{\circ}$ Seminário sobre Sustentabilidade, v. 1, p. 1-8, 2008.

SILVA, M. E. T. Resumo executivo do projeto rede de defesa e proteção animal da cidade de Curitiba. Prefeitura Municipal de Curitiba, 2009.

SIQUEIRA-BATISTA, R.; RÔÇAS, G.; GOMES, A. P.; COTTA, R. M. M.; MESSEDER, J. C. A bioética ambiental e ecologia profunda são paradigmas para se pensar o século XXI? Ensino, Saúde e Ambiente, v. 2, n. 1, p. 44-51, 2009.

SOUSA, J.M.M.; LOPES, C.A.T.; LANÇA, I.; LELIS, M.G.; PAVÃO, J.F. Mata atlântica: Educação ambiental para o ecoturismo e uso sustentável de uma unidade de conservação. Revista Nordestina de Ecoturismo, v. 1, n. 1, p. 54, 2008.

SOUZA, R. G.; SANTOS, M. L. Percepção ambiental dos usuários da Fazenda Santa Branca Ecoturismo (APA - Ribeirão João Leite), Teresópolis (GO). Revista Brasileira de Ecoturismo, v. 3, n. 3, p. 460-477, 2010.

TUAN, Y. Topofilia: um estudo da percepção, atitudes e valores do meio ambiente. São Paulo, Difel, 1980.

ULYSSÉA, M. A.; HANAZAKI, N.; LOPES, B. C. Percepção e uso dos insetos pelos moradores da comunidade do Ribeirão da Ilha, Santa Catarina, Brasil. Biotemas, v. 23, n. 3, p. 191-202, 2010.

VERÇOSA, A. H. Responsabilidade civil do Estado e de particulares em acidentes de trânsito provocados por animais: Análise da doutrina da responsabilidade civil e apanhado da jurisprudência nacional. Jurídico HighTech. Disponível em: <http://www.juridicohightech.com.br>. Acesso em 24 abr. 2013.

VIDOLIN, G.P.; MOURA-BRITTO, M. Análise das informações contidas nos autos de infração relativos à caça, cativeiro e comércio ilegal de mamíferos silvestres, Paraná - Brasil. Cadernos da Biodiversidade, v. 1, n. 2, p. 48-56, 1998. 
VIDOLIN, G. P.; MOURA-BRITTO, M.; BRAGA, F. G.; CABEÇAS-FILHO, A. Avaliação da predação a animais domésticos por felinos de grande porte no Estado do Paraná: implicações e estratégias conservacionistas. Cadernos da Biodiversidade, v. 4, n. 2, p. 50-58, 2004.

VILLAR, L. M.; ALMEIDA, A. J.; LIMA, M. C. A.; ALMEIRA, J. L. V.; SOUZA, L. F. B.; PAULA, V. S. A percepção ambiental entre os habitantes da região noroeste do estado do Rio de Janeiro. Escola Anna Nery Revista de Enfermagem, Rio de Janeiro, v. 12, n. 2, p. 285-290, 2008.

WELLS, M.; BRANDON, K. E. People and Parks: Linking Protected Area Management with Local Communities. Washington, DC, The World Bank, 1992.

ZAKRZEVSKI, S. B. B. Por uma educação ambiental crítica e emancipatória no meio rural. Revista Brasileira de Educação Ambiental, v.1, n. 0, p. 79-86, 2004.

revista brasileira educação ambiental 